CNSS Papers

DOE Weapons Laboratories' Contributions . to the Nation's Defense Technology Base

Siegfried S. Hecker
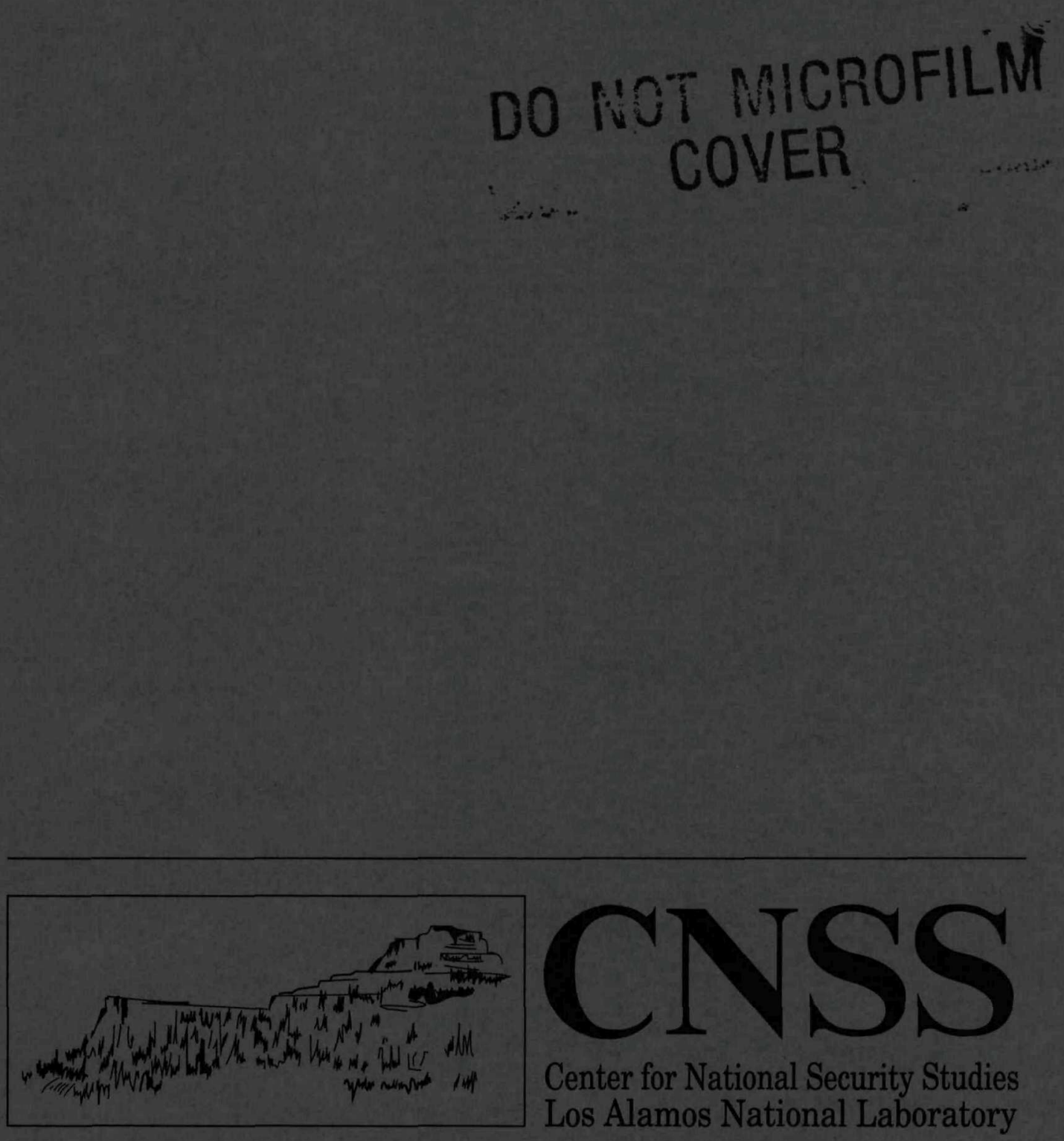


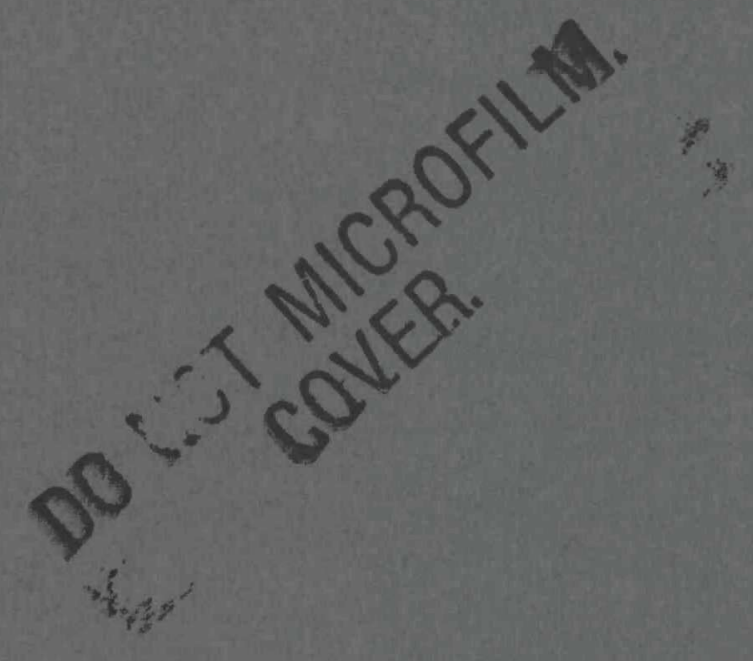

CENTER FOR NATIONAL SECURITY STUDIES

The Center for National Security Studies is a studies and analysis organization of the Los Alamos National Laboratory. Drawing on the broad knowledge at Los Alamos of science and engineering relevant to national security issues, the Center's research focuses on the interaction between technology and policy and on developing insights that may improve the relationship between the development of new technology and the achievement of national policy goals. The Center's staff includes both resident and visiting researchers.

The principal mission of the Center is to promote and conduct long-term research and analysis in the broad areas of arms control, national defense, low-intensity conflict and terrorism, energy security, and technological competitiveness. In addition, it provides insight about national security policy, strategy, and technology issues to the Laboratory staff, thus helping Los Alamos better address national needs. Finally, the Center serves as a focus for the exchange of ideas on international security issues for Los Alamos.

The Center documents its work in a number of publications. The Briefs are short informal papers commenting on topics which are appropriate to the Center's areas of interest. The CNSS Papers are more extensive documents which may be monographs, seminar talks, or workshop proceedings. The Reports are formal research papers or edited conference proceedings on topics appropriate for Center sponsorship. A book series, Issues in $\mathrm{Na}$ tional Security, will report the results of the Center's research on key national and international security issues. 
No. 9

April 1988

\title{
DOE Weapons Laboratories' Contributions to the Nation's Defense Technology Base
}

\author{
Siegfried S. Hecker
}

\section{DISCLAIMER}

This report was prepared as an account of work sponsored by an agency of the United States Government. Neither the United States Government nor any agency thereof, nor any of their employees, makes any warranty, express or implied, or assumes any legal liability or responsibility for the accuracy, completeness, or usefulness of any information, apparatus, product, or process disclosed, or represents that its use would not infringe privately owned rights. Reference herein to any specific commercial product, process, or service by trade name, trademark, manufacturer, or otherwise does not necessarily constitute or imply its endorsement, recommendation, or favoring by the United States Government or any agency thereof. The views and opinions of authors expressed herein do not necessarily state or reflect those of the United States Government or any agency thereof.
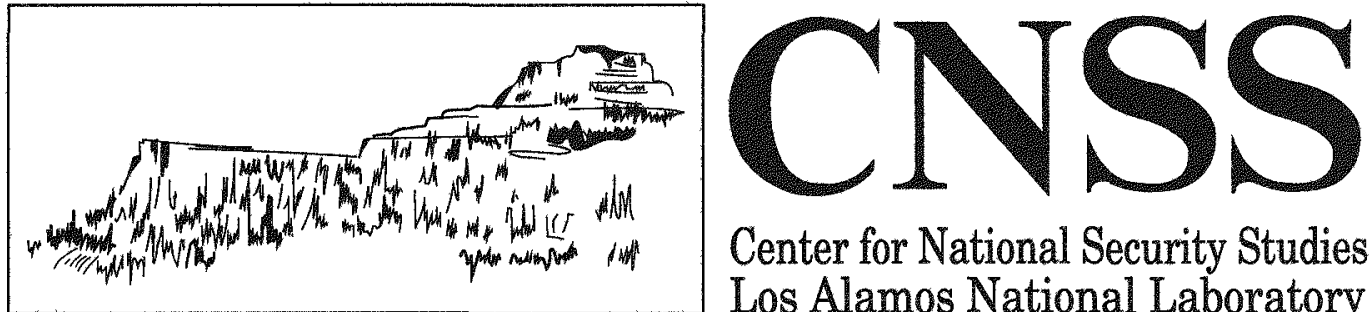

Center for National Security Studies Los Alamos National Laboratory 
SIEGFRIED S. HECKER is the Director of the Los Alamos National Laboratory. 


\title{
DOE WEAPONS LABORATORIES' CONTRIBUTIONS TO THE NATION'S DEFENSE TECHNOLOGY BASE
}

\author{
Siegfried S. Hecker
}

\section{SUMMARY}

International technological competition is becoming increasingly severe, and the U.S. technological lead in this competition is eroding on both the economic and the military fronts. It is imperative, therefore, that we coordinate the capabilities of the different sectors in the science and technology community that contribute to the defense technology base of the nation.

The technology base of the three Department of Energy (DOE) nuclear weapons laboratories and their mode of technology transition to applications have served the nation well by helping to maintain its nuclear deterrence. These laboratories also offer an exceptional potential to strengthen the Department of Defense (DoD) defense technology base.

The laboratories already perform over a half billion dollars of R\&D for the DoD. To optimize and enhance the role of the DOE laboratories, three suggestions are:

- Strengthen the DoD laboratories through personnel exchanges with the DOE laboratories.

- Complement the technology base of the private industry defense contractors through teaming arrangements with the DOE laboratories.

- Conduct an experiment with the DOE laboratories to try their methodology on a full DoD technology cycle from concept to production.

These recommendations will also promote a more stable, long-term relationship between the DOE weapons laboratories and the DoD and thereby benefit not only the nation's defense technology base, but also the nuclear weapons program. 



\section{FOREWORD}

This paper was prepared as the written statement for the March 18, 1988, hearing on the defense technology base by the Subcommittee on Defense and Industry Technology of the Senate Armed Services Committee. 


\begin{abstract}
The question of how the Department of Energy (DOE) weapons laboratories can contribute to a stronger defense technology base is addressed in testimony before the Subcommittee on Defense Industry and Technology of the Senate Armed Services Committee. The importance of the defense technology base is described, the DOE technology base is also described, and some technology base management and institutional issues are discussed. Suggestions are given for promoting a more stable, long-term relationship between the DOE weapons laboratories and the Department of Defense.
\end{abstract}




\section{CONTENTS}

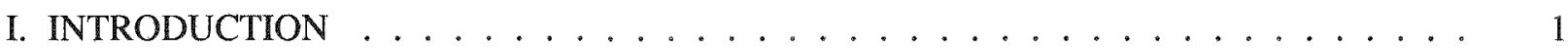

II. THE DEFENSE TECHNOLOGY BASE $\ldots \ldots \ldots \ldots \ldots \ldots$

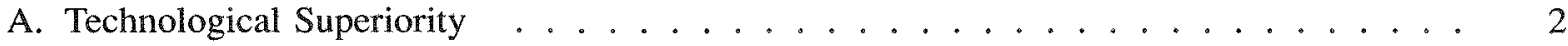

B. The Composition of the Defense Technology Base . . . . . . . . . . . . 3

C. Federal Support for Defense R\&D . . . . . . . . . . . . . . . . . . 4

D. Concerns about the Defense Technology Base . . . . . . . . . . . . . . . 4

E. Evolving Strategies and Requirements ................. . . 5

F. The Soviet Technology Base .................... 6

III. THE DOE TECHNOLOGY BASE $\ldots \ldots \ldots \ldots \ldots$

A. The DOE Nuclear Weapons Role . . . . . . . . . . . . . . . 6

B. The Research-to-Retirement Responsibility of the Weapons Laboratories . . . . . . 7

C. Nuclear Weapons R\&D and Production . . . . . . . . . . . . 8

D. The DOE Laboratories . . . . . . . . . . . . . . . . . . . . 9

IV. TECHNOLOGY BASE MANAGEMENT AND INSTITUTIONAL ISSUES _. . . . . 10

A. The Defense Science Board and Ad Hoc Advisory Committee Reports . . . . . . . 10

B. The DOE GOCO Experience ....................... 10

C. The Critical Requirements for a First-Rate Defense Laboratory . . . . . . . . . . 11

V. HOW THE DOE LABORATORIES CAN ENHANCE THE DOD TECHNOLOGY BASE 13

A. Los Alamos Examples of Technology Base Applications for DoD . . . . . . . 13

B. Relevant Technologies for Future Applications . . . . . . . . . . . 15

C. Recommendations for Enhancing the DoD Technology Base . . . . . . . . . 17

D. Recommendations for Enhancing Technology Transfer and Mission Support . . . . 19

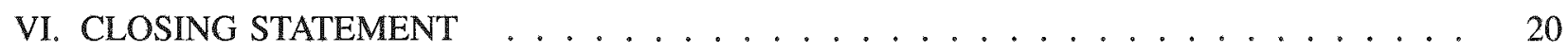

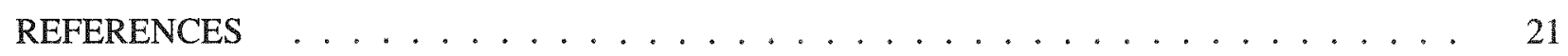

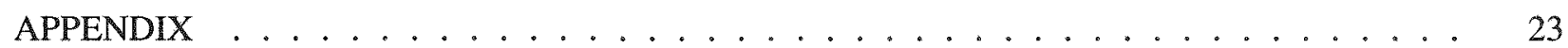




\title{
DOE WEAPONS LABORATORIES' CONTRIBUTIONS TO THE NATION'S DEFENSE TECHNOLOGY BASE
}

\author{
by
}

\author{
Siegfried S. Hecker
}

\section{INTRODUCTION}

The military strength of the United States, based on its fielded systems and forces, is built on a foundation of technological superiority. With the substantial increase in defense spending during this decade, need we be concerned about our technological superiority?

I believe the answer is yes. Our nation's technological edge is being challenged as it never has been before. We are fighting to compete on two fronts: the economic front with Japan, Eastern Asia, and Europe and on the military front with the Soviet Union. Our competition is investing heavily in research and technology.

In the economic area we watched for years as the Europeans, Japanese, and other East Asian countries increased their investment in R\&D and in their capacity to bring new ideas to commercial products. We had a technological edge. We may have thought it was insurmountable. It was not.

We cannot afford the same miscalculation in the area of national security. The Soviets continue to invest heavily in science and engineering. They have made impressive gains in the areas of their top priority, military and space technologies. They continue to place a premium on education and have $37 \%$ of the world's manpower in science and engineering compared with $9 \%$ for the United States.

The potential military consequences of losing either the economic or military competition are grave. Paul Kennedy in his widely read The Rise and Fall of the Great Powers ${ }^{1}$ points out that history has demonstrated the importance of strong economic underpinnings for great world powers. Kennedy develops the central theme that the relative position in both military power and economic capacity is what matters. Clearly, the two can no longer be considered separately as one ponders national security strategies.

The Japanese with their great ability to innovate - to bring ideas into the marketplace-- have contributed to the demise of entire industries in other countries by what one can call technological surprise. They have heightened international competition for consumer goods to the point where, today, the pace of high-technology innovation in the commercial sector often outstrips the development of military technology. This fast pace helps make commercial technology readily available for the military markets of potential adversaries and threatens our military technological superiority.

The federal budget deficit has put pressure on defense spending. There will be a natural tendency to concentrate on short-term military requirements, a trend that persisted even during the years of increased defense spending. Concerns about the defense technology base, our scientific and technical underpinnings that will provide options for future military systems, were recently expressed by the 1987 Defense Science Board (DSB) Summer Study on Technology Base Management ${ }^{2}$ and a report to the Subcommittee on Defense Industry and Technology, Senate Armed Services Committee, by an Ad Hoc Industry Advisory Committee. ${ }^{3}$

As a nation we must harness the resources of all sectors of our science and technology community to preserve the defense technology base that holds the key to our technological superiority and our 
national security. I will address primarily the question of how the Department of Energy (DOE) weapons laboratories can contribute to a stronger defense technology base. First, I will describe the importance of the defense technology base, describe the DOE technology base, and discuss some technology base management and institutional issues.

There are three messages that I would like to leave with you today.

First, international technological competition is becoming increasingly severe. There are many signs that the U.S. technological lead is eroding on both economic and military fronts. We must coordinate the capabilities of the different sectors in the science and technology community that contribute to the defense technology base.

Second, for over 45 years the DOE and its predecessor agencies have fostered an environment that developed outstanding laboratories for scientific research and technology development. The technology base of the three DOE nuclear weapons laboratories and their mode of technology transition to applications have served the nation well by helping to maintain its nuclear deterrence. These laboratories also offer an exceptional potential to strengthen the DoD defense technology base.

Third, the DOE nuclear weapons laboratories already perform over a half billion dollars of R\&D for DoD. I have three specific suggestions for optimizing and enhancing the role of the DOE laboratories:

- Help strengthen the DoD laboratories through personnel exchanges with the DOE laboratories.

- Complement the technology base of the private industry defense contractors through teaming arrangements with the DOE laboratories.

- Conduct an experiment with the DOE laboratories to try their methodology on a full DoD technology cycle from concept to production.

\section{THE DEFENSE TECHNOLOGY BASE}

\section{A. Technological Superiority}

The importance of technological superiority was demonstrated by the success of the Manhattan Project during World War II. The United States continued to depend on that technological superiority by relying on nuclear weapons for deterrence after the war. The principal role of early U.S. nuclear forces was to provide extended deterrence - to deter the Soviets from attacking or intimidating vital but exposed U.S. allies while permitting our allies to recover their military strength and political and economic well-being. Nuclear weapons provided security for our allies at far less cost than the remobilization of full-scale conventional forces.

While over the years nuclear forces have continued to play a vital role in national defense, emphasis has also been placed on conventional military forces and technology. Secretary of Defense Weinberger espoused the Doctrine of Competitive Strategies-the matching of Soviet numerical superiority with U.S. technically superior weapons. These concepts and related strategies rely on concepts such as the modern integrated battlefield, data fusion, advanced sensors, and smart weapons. Such concepts are successful only if our technology base is strong and dynamic and if we get the technology into the field.

In times of war, the ability of U.S. industry to mobilize to produce and deliver adequate quantities of superior-quality hardware is paramount. In times of peace, our ability to maintain technological superiority is a key element in maintaining that peace without a far larger commitment of men and materiel to the defense function.

Keeping peace through strength is a characteristic of deterrence. But deterrence of conflict at all levels is much more difficult to maintain, as the large number of regional conflicts during the last four decades testifies. Nevertheless, our ability to maintain strength and to project force anywhere necessary 
in the world is an essential element of our national defense policy.

As technical capabilities around the world increase, we must maintain the ability to respond rapidly to unforeseen developments in force structure or technology and be able to avoid major technological surprise. Our strength based on technological superiority depends inexorably upon a vigorous defense R\&D program-a sound science and technology base (I will refer to it as the technology base) that assures the flow of new ideas, concepts, products and systems.

The concept of deterrence is intended to maintain peace, and it is designed for the long term. We may reduce our arms and cut back on deployed forces as international tensions ease, but we should not endanger our security by eroding our technology base. It is the technology base that provides us with the ability to guard against technological surprise and the ability to respond quickly should we be challenged or threatened.

\section{B. The Composition of the Defense Technology Base}

The military R\&D process is well known. It is divided into six different categories, which I will briefly describe here for later reference.

Basic research (6.1) consists of relatively unstructured but high-quality and monitored research at universities, federal laboratories, and to some extent, private industry. Exploratory development (6.2) is designed to take those ideas with significant potential and test their readiness for military concepts. Advanced technology development-feasibility (6.3A) is aimed primarily at the transition of a promising technology to a fielded system. These first three categories are typically considered to comprise the Department of Defense (DoD) technology base.

Advanced development (6.3B) concentrates on programmatic development of systems. It takes the ideas that survive the first three categories and proves their performance in a systems context. The 6.4 (engineering development) and 6.5 (management and support) phases are concerned with the transition to production.

The technology base relies on people, institutions, and facilities. One of the greatest challenges we face is to continue to attract first-rate scientific and engineering talent into defense-related $R \& D$. The most important source of talent is the nation's universities. The Mansfield amendment, which severely restricted research to that directly supporting the mission of the defense agency, and the general decline of basic research (6.1) funding over the past 23 years (from $0.7 \%$ to $0.3 \%$ of the total DoD funding) have made access to that talent more difficult. Universities conduct $60 \%$ of the basic research in the United States, but curtailed basic research funding has limited their contributions to the defense technology base.

The federal laboratories continue to contribute to the defense technology base. The 74 DoD service laboratories play a major role. They perform a significant fraction of the 6.1 (32\%) and $6.2(43 \%)$ work and control or manage much of the rest of the technology base.

The DOE weapons laboratories have the primary responsibility for the nuclear weapons technology base. They and the other DOE laboratories have increasingly contributed to the DoD technology base as well. Other government laboratories, nonprofit laboratories, and federally funded research and development centers (FFRDCs), such as the National Bureau of Standards, Lincoln Laboratories at MIT, the Applied Physics Laboratory at Johns Hopkins University, the Jet Propulsion Laboratory, Southwest Research Laboratory, Battelle Columbus Laboratory, and others also contribute significantly.

Small and large private contractors are vital to a strong technology base. Their efforts are typically funded through Independent Research and Development (IR\&D) programs, which use discretionary funds generated from federally funded programs. These programs are used for technology base activities and allow private contractors to remain technologically competitive by selectively applying their resources to pursue advanced technologies.

The funding agencies play an important role in developing and nurturing the defense technology base. The DoD services work principally through their research offices and laboratories. The Defense Advanced Research Projects Agency (DARPA) has played a special role since its inception in the late 1950 s. It was formed as one of the responses to Sputnik to prevent the recurrence of such technological surprise and to help the United States maintain a military technological superiority. It concentrates on the high-technology end of defense research and development. In the past five years, the Strategic Defense 
Initiative Office (SDIO) has taken over the major DARPA projects on strategic directed-energy weapons and combined them into the goal-oriented SDI program. It has also taken on a significant responsibility in technology base development.

Numerous special facilities are critical for technology base development. These include the Aberdeen Proving Grounds, the White Sands Missile Range, the Nevada Test Site, and many others. All of these facilities with their people and institutions make up the defense technology base.

\section{Federal Support for Defense $\mathbf{R} \& \mathbb{D}$}

World War II demonstrated the importance of applying scientific knowledge to nationally compelling problems and the importance of the government playing a leadership and funding role. The development of nuclear weapons, radar, proximity fuses, and advanced communications gear were scientific marvels that changed the course of military warfighting and strategy. After the war, the mission-oriented agencies-DoD and the Atomic Energy Commission (AEC)-supported most of the R\&D. The results served both the agencies' purposes and the industrial sector well. Universities began to combine a charter of basic research in areas of interest to the defense technology base with their primary mission of education.

The launch of Sputnik in 1957 brought shock and surprise together with a move by the federal government to enhance the U.S. technology base. A major component of this effort was increasing support for R\&D at U.S. universities. This support served both military and industrial competitiveness well.

However, from 1968 to 1980 , defense spending as a fraction of Gross National Product (GNP) declined significantly (from $9.6 \%$ in 1968 to $5.0 \%$ in 1980). Investment in defense research, development, testing, and engineering (RDT\&E) decreased proportionately with overall defense spending. The technology base as a fraction of RDT\&E declined during this period. Significantly less defense research was funded at universities.

In the $1980 \mathrm{~s}$, defense spending increased to the current level of approximately $6.5 \%$ of GNP. Support for defense RDT\&E increased both as a fraction of defense spending (from about $10 \%$ of total defense in 1980 to approximately $12 \%$ today $^{4}$ ) and as a fraction of federal outlays. The increase as a fraction of federal outlays was larger because the increase in defense was accompanied by a decrease in civilian funding. The federal outlays for defense R\&D versus civilian R\&D changed from $50 \%-50 \%$ in 1980 to $65 \%-35 \%$ today. The total dollars for technology base funding also increased, but at a much slower rate than that for RDT\&E. Today, 6.1 through $6.3 \mathrm{~A}$ activities represent $2.9 \%$ of total defense spending. ${ }^{2}$

\section{Concerns about the Defense Technology Base}

The DSB Study Group ${ }^{2}$ stated that there is increasing risk that the United States is losing the technological advantage on which it bases its strategy for military superiority. It expressed great concern over the management of the defense technology base. It also concluded that the ability to rapidly move technology from the research stage to fielded systems is a problem and a key issue standing in the way of truly successful defense R\&D management. The Ad Hoc Industry Advisory Committee ${ }^{3}$ stated that current DoD acquisition practices are reducing, if not eliminating, the incentive to innovate and are discouraging the investment of private funds in the next generation of technology.

I find several reasons for concern over the defense technology base:

- A concentration on short-term problems and direct military relevance of almost all defense-supported R\&D for at least two decades. This concentration includes focusing research efforts increasingly on a few highly visible projects instead of maintaining a diversity of exploratory research. The current budget deficit is likely to increase the pressure for short-term payoff.

- A difficulty of rapid and effective transition of advanced technology to deployed systems and forces. 
- A lack of coordination of the contributions of the different sectors that compose defense science and technology.

- A preoccupation of the federal government with audits and regulations in an attempt to clean up military procurements. The effect on the management of R\&D has been to limit flexibility and innovation.

- A world that has rapidly become more competitive militarily and economically with a complex interplay between the two.

- A potential shortage of highly trained, innovative scientists and engineers in the future to preserve our military and economic strengths. Although our universities are still the envy of the world, more than half of the graduate students in engineering and approximately one-third in the physical sciences are foreign nationals. Just as alarming is the fact that the foundations of precollegiate education are seriously eroding, threatening to dry up the supply of adequate U.S. talent for universities and the job market.

\section{E. Evolving Strategies and Requirements}

The INF Treaty and the START negotiations demonstrate the willingness of the nuclear powers to start on a road to meaningful, equitable, and verifiable nuclear arms reductions. The road to arms reductions must be traveled not only with strong determination but also with great caution. National security policy must move toward a greater reliance on conventional weapons and defenses. Treaties designed to reduce the nuclear arsenals must be crafted to increase U.S. security by decreasing the risk of nuclear war, not simply to reduce the number of weapons. Large reductions of nuclear weapons by the major powers will require careful restructuring of nuclear forces to preserve global stability. Nuclear deterrence will remain the cornerstone of U.S. national security policy for the foreseeable future, even in an atmosphere of mutual arms control and arms reduction.

The technical competence for nuclear deterrence rests heavily on the shoulders of the three DOE weapons laboratories, Los Alamos, Lawrence Livermore, and Sandia National Laboratories. Smaller nuclear arsenals will still need to be safe, secure, effective, and survivable, which requires modernization. The expertise of the laboratories will be required to maintain the stockpile and verify arms control agreements. And, most importantly, the broad technology base at the laboratories will still be required to guard against technological surprise, which becomes even more important in a world with fewer nuclear weapons.

There is a general consensus that the United States must develop a long-term strategy that relies more heavily on conventional weapons and defenses. One recent study conducted for the DoD by the Commission on Integrated Long-Term Strategy ${ }^{5}$ calls for discriminating military responses that do not depend only on threats that are expected to provoke our own annihilation.

A specific recommendation of the Commission is:

We must diversify and strengthen our ability to defeat aggression. To this end, we and our allies need to exploit emerging technologies of precision, control, and intelligence that can provide our conventional forces with more selective and more effective capabilities of destroying military targets.

The Commission further states:

Military technology will change substantially in the next 20 years. We have depended on nuclear and other advanced weapons to deter attacks on our allies, even as the Soviets have eliminated our nuclear advantage. If Soviet military research continues to exceed our own, it will erode the qualitative edge on which we have long relied.

It also suggests that both our conventional and nuclear posture should be based on a mix of offensive and defensive systems. 
Clearly, new strategies and directions for our national security will require a continued reliance on technology.

\section{F. The Soviet Technology Base}

The Soviets have continued their own uninhibited drive toward technological superiority. They employ 12 million scientists and engineers, compared with slightly less than 3 million for the United States. They graduate 450,000 students per year in the natural sciences and engineering, more than twice the U.S. numbers.

In the military and space arenas, which get priority in the Soviet Union, they have made remarkable progress. Thirty years after Sputnik they significantly outclass the United States in heavy launch capability. Soviet astronauts have also logged nearly three times as many hours in space as their U.S. counterparts. In military technologies, they are world leaders in such areas as high-pressure physics (both static and shock loading); light-weight, high-strength materials; lasers; and particle accelerators. In fact, the radio-frequency quadrupole linear accelerator, developed at Los Alamos and now the basic building block for Los Alamos SDI technologies, was first invented in the Soviet Union.

General Secretary Gorbachev admitted late last year that the Soviets have a vigorous SDI R\&D program. It is generally believed that the Soviets have more than 10,000 researchers in more than six major facilities dedicated to laser research. Much of this would be directly applicable to SDI concepts and greatly exceeds the U.S. effort. It is also alarming to see a significantly increased effort in areas such as chemical and biological agents and genetic engineering.

I believe that their drive towards technological superiority will in no way be tempered by international agreements to control armaments. In fact, the following statement made recently by V. Falin, who is responsible for official announcements on Moscow policy as the head of the state-run Soviet press agency, Novosti, and former Ambassador to West Germany, indicates that the military will increasingly turn to science:

"We won't copy you anymore, making planes to catch up with your planes, missiles to catch up with your missiles. We'll take asymmetrical means with new scientific principles available to us.

"Genetic engineering could be a hypothetical example. Things can be done for which neither side could find defenses or countermeasures, with very dangerous results. If you develop something in space, we could develop something on earth. These are not just words. I know what I'm saying."6

In the next section, I will describe the DOE technology base and a method of integrating this base into systems acquisition.

\section{THE DOE TECHNOLOGY BASE}

\section{A. The DOE Nuclear Weapons Role}

The responsibility for the design and production of nuclear weapons in accordance with national policy resides with the DOE. The responsibility for ensuring that these weapons remain reliable, safe, secure, and responsive to national policy needs throughout their lifetimes in the national stockpile is shared with the DoD. The DOE responds to the President's annual nuclear weapons stockpile memorandum, which specifies national needs for numbers and characteristics of weapons to support national policy, and to legislation from the Congress. The DOE is also responsible for providing the necessary $R \& D$ and operating the nuclear weapons production complex to assure the viability of this nation's deterrent and to guard against technological surprise.

To fulfill these responsibilities, the DOE supports a complex of institutions to design weapons in response to present and future needs, to manufacture the weapons and produce the special materials necessary for production, and to monitor those weapons throughout their lifetimes. Three national lab- 
oratories have the responsibility for the design of nuclear weapons and for maintaining the supporting structures that enable them to enter the national stockpile. Los Alamos and Lawrence Livermore national laboratories have the statutory responsibility for the design of the actual nuclear components of the weapons. As a full partner, the Sandia National Laboratories support the two nuclear weapons design laboratories by designing the nonnuclear components of the warhead system.

A network of integrated facilities operated for the DOE by private contractors produces the fissionable material for weapons and manufactures and assembles the weapons in accordance with the designs specified by the laboratories. Underground nuclear testing, which is an integral part of the research, development, and deployment process, is conducted by the laboratories at the DOE Nevada Test Site. The atomic energy defense activities are the responsibility of the DOE by the statutes of the Atomic Energy Acts of 1946 and 1954, as amended.

The DOE weapons laboratories have a responsibility that is unique in the defense complex. It stems from the recognition that the highest levels of scientific expertise are critical for the successful development of highly sophisticated defense technologies. This necessity was recognized at the very start of the Manhattan Project. Scientists needed a better understanding of the underlying physics and microscopic physical processes to design nuclear weapons than the much more empirical understanding that was needed to design pre-World War II conventional weapons.

Careful attention to a host of complicated physical mechanisms was required. Failure to comprehend details of microscopic processes, like the variation of fission probability with neutron energy, would have doomed the project to failure. Similarly, extensive use of theory and sophisticated modeling were imperative to success. The superb leadership of outstanding academicians during the Manhattan Project contributed to the project's success and left a legacy of attention to scientific methods of investigation that are the bedrock of the Los Alamos National Laboratory. The Manhattan Project also fostered an unprecedented cooperation of universities, industry, and government working closely to translate basic research directed towards national goals into practical applications. Because of this cooperation, Los Alamos was, and still is, operated by the University of California.

\section{B. The Research-to-Retirement Responsibility of the Weapons Laboratories}

The DOE weapons laboratories have a broad research-to-retirement responsibility for nuclear weapons. They are primarily responsible for research, development, and design but also have continuous oversight responsibility through manufacturing, stockpile, and finally, retirement. This broad research-to-retirement responsibility has made the DOE weapons laboratories an essential element of deterrence. It has also fostered an atmosphere of innovation, with the ability to transfer basic ideas into concepts and hardware useful to the military. Innovation requires close coordination of research, development, manufacturing, and customer relations.

Los Alamos has a vigorous research program encompassing many of the basic disciplines critical to nuclear weapons. Research at the DOE weapons laboratories is imperative because universities, which conduct $60 \%$ of the basic research in the United States, are generally not inclined nor equipped to work on many of the ideas relevant to nuclear weapons.

The weapons laboratories have been able to foster an atmosphere that is particularly conducive to multidisciplinary research, easily crossing the boundaries of traditional physics, chemistry, mathematics, materials, or engineering departments at universities. They have also earned a reputation for developing and operating special large research facilities, both for their staffs and for university and industry researchers. For example, at Los Alamos we have the largest scientific computing capability in the United States, equivalent to 25 Cray 1 supercomputers. With this capability we are developing novel, ultrahigh-speed computer graphics techniques that may ultimately allow us to visualize complicated timedependent, three-dimensional hydrodynamics effects with the potential of greatly enhancing the nuclear weapons design process.

Nuclear weapons design and development are conducted at the two design laboratories, Los Alamos and Lawrence Livermore. We integrate theory, design, testing, and engineering into a successful program. Successful integration requires not only individual scientific brilliance but also teamwork and engineering. The current program examining the concept of an earth-penetrating weapon (EPW) to hold at risk hardened 
or deeply buried targets is an excellent example. A successful weapon requires innovative new physics and extraordinary engineering to have the warhead penetrate the ground, survive, and detonate. We work closely with Sandia National Laboratories on the engineering aspects of the EPW concept and other nuclear weapons systems.

Manufacture and assembly of nuclear weapons are the responsibilities of the DOE/Defense Programs production complex. The DOE laboratories have an important role in production oversight. There is constant interchange between the nuclear weapons manufacturing community and laboratory designers and engineers during the production cycle. In fact. Los Alamos designers and engineers consistently, and very successfully, work producibility and manufacturing efficiency into their designs.

The two design laboratories are involved in process development to ensure a smooth flow of the product through the manufacturing lines. At Los Alamos we are particularly proud of the fact that because of excellent design, engineering, packaging, and continued integration with the production facilities, our warhead systems, most recently the W80 (for the Air-Launched Cruise Missile and Sea-Launched Cruise Missile), W76 (Trident I), and W78 (Minuteman III) all have, or have had, very low production costs and few or no schedule delays. The B61 bomb is also an excellent example of a robust and flexible system; over the years we have upgraded the safety and security of this single system to meet evolving military requirements.

Producibility is a critical function and requires frequent interchange during development, test, and hardware phases early in the program. This close interface continues through the production process and while systems are in the stockpile through an integrated production and surveillance program that supports each plant in maintaining the stockpile. Finally, the laboratories are involved in the retirement of all nuclear systems. In essence, we see the weapon through all its stages and provide a life-time guarantee.

This breadth of responsibilities for one family of institutions is truly unique in the U.S. defense complex.

\section{Nuclear Weapons R\&D and Production}

I will describe briefly here and in some detail in the Appendix the methodology of nuclear weapons development. It is necessarily peculiar to and tailored for nuclear weapons. However, I believe that it may offer some ideas that can be exploited for some conventional weapons systems.

The process for developing and producing nuclear weapons is divided into eight "phases." Phase 1 (concept study) defines weapons concepts related to a perceived or expressed need. Phase 2 (feasibility study) determines the technical feasibility, the development schedule, program cost estimates, and resource requirements for the weapons concepts in question. These two phases along with basic research constitute a technology base analogous to the DoD technology base. Phase 2A (design definition and cost study) identifies the baseline design or designs that best balance resources and requirements to establish a tentative development and production schedule. Phase 3 (development engineering) establishes a tested, manufacturable nuclear weapon design.

Phase 4 (production engineering), phase 5 (first production), phase 6 (quantity production and stockpile), and phase 7 (retirement) are associated with stockpile production and retirement as described in the Appendix. Basic research is considered prephase 1 and not specifically identified in this process, but very important for generating new ideas.

This DOE methodology is designed to encourage a smooth and steady flow of ideas from the technology base activities (prephase 1) to the concept and feasibility phases because the weapons laboratories play a key role in all of them. This flow does not always happen in practice, but there is always significant exchange of ideas (both technologies and requirements) in the early phases of weapons development. A Phase 1 study may be initiated by either the laboratories or the military. The laboratories participate actively in preliminary military characteristics and stockpile-to-target sequences. There is a healthy dialogue among researchers, designers, engineers, and the military.

Phase 2 is conducted jointly between the laboratories and the military services. It includes an examination of designs, testing, production processes, and resources in a realistic environment. It involves technology demonstration before committing to a full-scale engineering decision. This phase is crucial 
in expediting the transition of new technologies. By the nature of the DOE methodology, there is an intense interaction between the laboratories and the military services during all eight phases.

The DSB Study Group ${ }^{2}$ recommended employing the $6.3 \mathrm{~A}$ phase of the DoD R\&D process for Advanced Technology Transition Demonstrations (ATTD) to sharpen the DoD's focus on technology transition. These demonstrations should help determine both technical feasibility and field utility without being committed to a defined systems development program and full-scale engineering development. This concept is very similar to the first three phases of the DOE methodology and one to which the DOE laboratories could contribute. I will develop this point in a later section.

\section{The DOE Laboratories}

The DOE manages 33 laboratories that represent the most comprehensive system of federal laboratories for science and technology. The nine multiprogram laboratories have the bulk of the funding among the 33, with annual operating budgets totaling $\$ 5$ billion, which represents approximately $8 \%$ of the total federal R\&D outlay. And of these nine multiprogram laboratories, the combined annual budgets of the three nuclear weapons laboratories are approximately $\$ 3$ billion, or $5 \%$ of the federal R\&D expenditures. I will brieffy describe the activities at Los Alamos before discussing the other DOE laboratories.

Los Alamos National Laboratory. Los Alamos was established during World War II to develop the atomic bomb that ended the war. The Manhattan Project was an effort of unprecedented proportion and of utmost national urgency. The successful development and production of the atomic bombs marked not only an enormous scientific and technological accomplishment but also the beginning of big, projectoriented government R\&D laboratories. The Laboratory's primary mission today remains the development of nuclear weapons technology to maintain this nation's nuclear deterrent. As mentioned above, we also share the responsibility for the safety, security, production oversight, surveillance, and retirement of nuclear weapons.

The nuclear weapons technology activities account for slightly over one-half of the Laboratory's $\$ 890$ million budget. The responsibilities for nuclear deterrence and guarding against technological surprise have allowed us to maintain a strong and broad technology base.

During the past decade, Los Alamos has broadened its focus to include nonnuclear defense problems. Currently, approximately one-quarter of the Laboratory's effort is in this area. We are bringing to bear a wide range of multidisciplinary technical talent on a variety of advanced concepts including advanced conventional munitions and strategic defense.

The remaining one-quarter of the Laboratory's effort is in the nondefense arena. These programs are primarily in the areas of basic research, energy, health, and space. Our experience has demonstrated that an outstanding basic research program and a challenging set of nondefense programmatic efforts addressing important national problems are key to an excellent defense laboratory.

The DOE Multiprogram Laboratories. Nine of the DOE laboratories are designated multiprogram laboratories-Argonne National Laboratory, Brookhaven National Laboratory, Idaho National Engineering Laboratory, Lawrence Berkeley Laboratory, Lawrence Livermore National Laboratory, Los Alamos National Laboratory, Oak Ridge National Laboratory, Pacific Northwest Laboratory, and Sandia National Laboratories-with comprehensive missions in defense, energy, and basic research. Their annual operating budgets are close to $\$ 5$ billion and represent approximately $8 \%$ of the total federal R\&D outlay. In addition to the three weapons laboratories, Idaho National Engineering Laboratory also is primarily defense oriented. The other five have energy and research missions. The DOE also manages a number of single-purpose laboratories such as the Fermi National Accelerator Laboratory and the Stanford Linear Accelerator.

Taken together, the DOE laboratories form a superb technical resource for the nation. They contribute strongly in basic research and complement research at universities with multidisciplinary research on complex problems and research at large facilities. In fact, the DOE laboratories have designed, developed, and operated many of the nation's large research facilities such as reactors, pulsed-neutron sources, synchrotrons, and high-voltage electron microscopes. These are typically operated as user facilities for university and industrial researchers.

In the area of technology development, the DOE laboratories have concentrated their efforts in defense 
and energy technologies with some activities in health and space. Recently they have expanded their efforts in health and space and have initiated programs on environmental R\&D and technology transfer to the private sector in an attempt to have the nation benefit more fully from the significant investment in R\&D at the laboratories. In my opinion, technology development efforts outside of nuclear weapons and nuclear energy programs have met with mixed success. I have discussed the problems and opportunities at previous testimonies. ${ }^{7-9}$

\section{TECHNOLOGY BASE MANAGEMENT AND INSTITUTIONAL ISSUES}

Several studies have concluded that the management and institutional issues associated with the defense technology base are as serious as the technological ones. This section discusses the critical requirements for a first-rate defense technology base, which revolves around people, their goals, those of organizations, and ways of achieving organizational results without losing creativity and productivity. In the final analysis, the quality of the technology base depends upon people, the scientists and engineers conducting the work and the leadership and vision of managers who direct it.

\section{A. The Defense Science Board and Ad Hoc Advisory Committee Reports}

The DSB Study Group ${ }^{2}$ looked in detail at technology base management in the DoD. The Study Group was unanimous in its view that the quality of technical people at all levels including both managers and performers is a central issue. Without good people, the entire system suffers. Other problems cited by the Study Group involve civil service personnel practices, military staffing of R\&D billets, focus on short-term versus long-term research, micromanagement, and a slow transition of ideas from research concepts to hardware.

The DSB study calls for each of the federal laboratories to have an identifiable mission. There should be a focus and a critical mass of technical skills. And, the study concludes that the problem of rapid technology transition to a fielded system is one of the key issues of R\&D management. The Study Group proposes a concept of Advanced Technology Transition Demonstrations (ATTDs) to build and test experimental systems in a field environment.

The Ad Hoc Industry Advisory Committee ${ }^{3}$ sounds alarm about the negative changes in independent research and development (IR\&D) for contractor agencies. The Committee states that ceilings on government-allowed IR\&D costs imposed the past several years inhibit industry's investment in technology base research that would lead to advanced technologies and new products. In addition, the Committee claims that there are increased scrutiny, reporting requirements, and a push for relevance to near-term military requirements that make IR\&D programs less effective. It recommends that the government accept its proportionate share of IR\&D costs instead of imposing a ceiling on each contractor.

\section{B. The DOE GOCO Experience}

Government-owned, contractor-operated (GOCO) laboratories were established during and after World War II as a way to bring first-rate scientific talent to bear on urgent technological problems. Contractor operation was also chosen specifically to circumvent the cumbersome government bureaucracy and expedite getting results in a goal-oriented project. This unique system began with the Manhattan Engineering District of the War Department during World War II; management of the system was later transferred to the Atomic Energy Commission. The Atomic Energy Acts of 1946 and 1954 expressly authorized management contracts with industrial and academic organizations.

The Manhattan Engineering District united government, industry, and university talent to conduct research and to design, build, and operate facilities for the production of a new weapon. Security and urgency were paramount. Almost everything about the project was at the frontier of scientific and technical knowledge. The risks were formidable. Only the compelling needs of war could have convinced universities and industries to accept such roles. 
The fundamental elements of the wartime management relationship are still viable today. The contractors recognize the authority of the government over the program and the government's need for full access to information concerning the contractor's performance. The government recognizes that the contractors are established organizations with proven technical and administrative capabilities. Both the contractors and the government recognize that the contractors must exercise their initiative and ingenuity in carrying out the contract work.

The government has found that the nuclear weapons program is best served by this unique management relationship. The current management contracts allow the DOE laboratories to recruit scientists more effectively than if they were civil service laboratories. The government determined in the beginning, and has reaffirmed at each contract renewal, that the program's best interests are served by having the University of California and AT\&T operate the nuclear weapons laboratories. The quality of the staff, the quality of the work, and innovation and creativity are best served by relying on these two parent organizations to manage the scientific and engineering activities of these three laboratories.

As a result of the management contract, the government has been able to tap the personnel resources of industry and universities, to use the procurement flexibility of private organizations, and to gain continued access to industrial technical knowledge and managerial expertise. The managing contractor relationship has been credited by most observers as a significant contribution to the success of this nation's R\&D efforts in nuclear defense.

In 1983 the Federal Laboratory Review Panel of the White House Science Council issued its report [Packard Report]. ${ }^{10}$ The Panel made an extensive survey of both GOCO and GOGO (government-owned, government-operated) laboratories. The Panel found those laboratories with well-defined missions and close interactions with the users of their research to be the most effective. They also found that some agencies gave excessively detailed management direction to the laboratories.

The Panel also stated that national interest demands strong collaboration of federal laboratories, universities, and industry. Three recommendations dealt with this area. One suggested that the federal government simplify its procurement policies to encourage a greater degree of contracting for R\&D. The Panel expressed its belief that laboratory directors were not allowed enough flexibility to exploit innovative scientific opportunities.

In July 1985 the President's Blue Ribbon Task Group (BRTG) on Nuclear Weapons Program Management ${ }^{11}$ released its report on the fiscal accountability and discipline in the nuclear weapons program. The report stated:

The three national laboratories that conduct nuclear weapon R\&D-Lawrence Livermore, Los Alamos, and Sandia-have long traditions of managerial discretion in defining research programs and in allocating resources quite unlike most of the nation's defense laboratories. Their technical accomplishments have been impressive. Successive generations of weapons have been introduced into the nation's stockpile, generally on schedule, while meeting increasingly high standards of nuclear safety and high performance specifications.

\section{The Critical Requirements for a First-Rate Defense Laboratory}

As implied above, the ability to attract and keep the best people is key. In research and development, a small percentage of unusually talented individuals can have enormous impact. A first-rate laboratory must have a strong primary mission, competent leadership, a creative environment, and interactions with peer organizations and universities. I will expand briefly on each of these.

A clear mission recognized and supported by the funding agencies, the Administration, and Congress provides the long-term, stable support for high-risk ventures in science and technology. Risk underlies the basic nature of research. It is only individuals or institutions that have the self-confidence provided by a solid mission and stable support that take the necessary risks and are willing to tackle long-term problems. The loss of such a mission and support undermines confidence and produces a culture averse to risk.

Focus is a corollary issue. Without a clear mission and the focus it provides, the laboratory cannot 
resist the forces that can quickly dilute its efforts and fragment its lines of authority and reporting into numerous, independent efforts. This fragmentation causes laboratory managers to lose control of the effort, becoming bookkeepers rather than leaders. The sponsor also loses the benefit of having work conducted in the large and capable interdisciplinary environment of the laboratory.

Leadership must develop a vision for the laboratory and articulate that vision to the workers. Visionary leaders must provide stability and flexibility, accept new ideas, and promote change. They must balance flexibility and accountability.

The laboratory has to have the flexibility to pursue research wherever it may lead. Yet, management must balance this flexibility against mission, budgets, and skills. The size of an R\&D institution is also important as pointed out by Hans Mark. ${ }^{12}$ There is a lower size limit to ensure sufficient flexibility for people to strike out into new territory. The upper limit is determined by management's difficulty in staying intellectually on top of the institution. By looking at federal laboratories, Mark pointed out in 1984 that the appropriate bounds may be 1000 to 7000 employees.

A first-rate laboratory must establish an atmosphere of creativity and challenge to attract the best people. There has to be a high-quality environment for research, one in which the best researchers have the tools, flexibility, and incentives to do their best. Creativity must be encouraged and rewarded by the institution's value system. The emphasis must be on the product, not the process. There must be the freedom to publish (within the bounds of classification), a premium on patents, and recognition for accomplishing the goals of a mission-oriented project.

A significant part of the environment needed to attract the best people and keep them productive is useful interaction with other researchers at universities, other laboratories, and industry. Los Alamos has been uniquely fortunate in that regard in that when the scientists who founded the Laboratory returned to their academic or industrial positions at the end of the Manhattan Project, they retained their personal and professional ties with the Laboratory. Continuing interaction with them was a valuable source of information, objectives, and fruitful collaboration on a large number of fundamental investigations. The strong ties to academia have remained a trademark of Los Alamos. Our scientists and engineers continue to interact closely with universities and peer institutions.

To ensure a first-rate high-technology defense laboratory, our experience has shown that an outstanding basic research program and programs to develop nondefense technologies are key ingredients to excellence. Nondefense basic and applied research is fundamental to attracting the best professional staff. The peer-reviewed research literature, the unclassified scientific popular literature, and publicly visible accomplishments are keys to institutional reputation and ultimate success in mission accomplishment. Ties to universities, where most of our country's basic research is done, ensure an inflow of talented new graduates to feed the professional work force. Defense programs typically have much weaker university ties.

At the DOE weapons laboratories, nondefense basic and applied work is done in an environment oriented toward national defense. Thus, multiple payoffs are common and occur quite naturally. While contributions are made to the solution of nondefense problems and significant additions are made to the international scientific knowledge base, considerations of potential defense applications of research results come as a natural by-product. For example, in our Fluid Dynamics Group, innovative computational fluids models operating on supercomputers have been developed for modeling the complicated combustion and flow processes in internal combustion engines. Collaborating scientists in the same group use similar approaches for modeling the dynamics of fluids in nuclear weapons and in the complicated penetration of armor by very high speed materials. The payoffs to the defense programs are quite substantial and very timely.

Such multiple payoffs abound in a first-rate defense laboratory and are increasingly important as stress increases on national budgets. Payoffs occur in both directions. Results from defense programs can also benefit nondefense problems, and technology transfer occurs most effectively in institutions with both types of programs.

The GOCO system of managing the nuclear weapons laboratories has served the nation well. Despite the successes attributed to the contract management concept, a significant erosion of enlightened policies has occurred with each passing year. Many of the Congressional, administrative, and regulatory requirements are translated into strict regulations by the executive agencies. These regulations have 
limited the flexibility, discretion, and long-term, high-risk orientation necessary for excellent research organizations. In addition, the regulatory requirements have eaten substantially into operating budgets and efficiency. The prestigious review panels cited above expressed the need to keep flexibility and discretion and minimize micromanagement and overregulation to maintain the excellence of the DOE national laboratories.

The entire area of work for others that encompasses the laboratories' interactions with the DoD and industry should be streamlined. The accounting, contracting, and intellectual property rights practices are overly restrictive and not designed to take maximum advantage of the laboratories.

\section{HOW THE DOE LABORATORIES CAN ENHANCE THE DOD TECHNOLOGY BASE}

As I have pointed out, the DOE technology base has, to a large extent, developed separately from the DoD technology base. It has been only in the last decade that the DOE laboratories have been substantially involved in nonnuclear weapons and defense. During this time, there has been some integration of the two technology bases and their applications. I will provide some examples of how Los Alamos National Laboratory has used its technology base for DoD applications.

\section{A. Los Alamos Examples of Technology Base Applications for DoD}

1. The Free-Electron Laser (FEL) Program. Immediately after the discovery of the free-electron laser principle, $R \& D$ in that field began in the DOE laboratories and resulted in a high level of expertise in FELs and high-power optics. The topic was of interest because it was relevant to DOE's isotope separation program: the wavelength of the laser light was adjustable (required for isotopic selectivity) and high power levels could be achieved (important for production considerations). By the early 1980s, DARPA and the Army recognized the potential of the FEL for directed energy weapons for ballistic missile defense. The FEL subsequently became a part of the SDI program.

Today, the potential for the use of FELs in SDI ground-based and space-based weapons remains attractive, and the DOE laboratories are major participants in the SDIO Directed Energy Program. The thrust of the present program is to evaluate the effectiveness of several technical approaches (the induction accelerator and radio-frequency accelerator approaches) and select one as the baseline technology for a moderate-power ground-based FEL to be built at the White Sands Missile Range. The program will be used to verify the integrability of the component technologies and to test the effectiveness of the methods used to propagate the powerful beam through the atmosphere.

2. The Neutral Particle Beam (NPB) Program. The DOE expertise in accelerator technology and control systems obtained as a result of the design of the Clinton P. Anderson Meson Physics Facility (LAMPF) research accelerator and the Pion Generator for Medical Irradiations (PIGMI) program, coupled with DOE expertise in radiation sensors used for nuclear weapons testing, gave Los Alamos an additional opportunity to support SDIO through research on the development of a neutral particle beam directed-energy weapon (DEW). Such systems address the basic DEW mission and resolve a crucial battle management issue of discrimination between the relatively few weapons and the large numbers of decoys for mid-course engagement. The NPB system is capable of interactive discrimination because of its ability to interrogate the target and monitor the resulting signals.

The NPB program is presently in the 6.2-6.3A phase. The major effort is at Los Alamos and is presently funded at the $\$ 80$ million a year level. The activity consists of the BEAR (Beam Experiment Aboard Rocket) project, whose objective is to determine the operability of a suitably designed particle accelerator in space (the first such experiment of its kind) and the GTA (Ground Test Accelerator), whose purpose is to build and integrate (with industry) a neutral particle beam device to demonstrate weapon parameters of an entry-level NPB system. 


\section{Armor Penetration Applications}

a. Uranium-Tungsten Long-Rod Penetrator. As part of their nuclear weapons development mission, the DOE laboratories have developed unique capabilities in the processing and fabrication of uranium and a broad expertise in materials properties, in the preparation of unusual materials and alloys, and in the properties of high explosives. It was natural to apply this knowledge to the solution of the Army's uranium-tungsten long-rod penetrator problem. Previous versions tended to disintegrate on firing or did not "fly" straight. Los Alamos developed an integrated uranium-tungsten composite material that resolved these difficulties as well as issues related to thermal expansion and materials interface. The end product was superior. The technology has been transferred to the services, and its application is in the acquisition process.

b. Armor-Piercing Kinetic-Energy Rounds. A more mature application of the Laboratory's capability in uranium processing and fabrication was our response to the Air Force's request that we identify the simplest and most effective uranium alloy that would have the required operational attributes. We responded with the development of the uranium-3/4\%-titanium alloy that was used in the GOW-8 for the Air Force's A10 close-support mission. Later, the Army adopted this material for its 105-mm tank cannon long-rod penetrator rounds on the M60 and M1. When the 105-mm equipment was replaced by $120-\mathrm{mm}$ cannons, the U-3/4\% $\mathrm{Ti}$ alloy remained the material of choice. It remains the material of choice for all high-performance kinetic-energy rounds that are armor-penetrating and fin-stabilized and that discard sabot (APFSDS). Millions of such rounds are in the stockpile.

c. Long-Standoff Penetrator (LSP). Precision explosives have been an integral part of weapons design and manufacture since Manhattan Engineering District days. DOE and DoD share the interest in shapedcharge design and it was natural to apply the Laboratory's talent to DoD shaped-charge requirements. Significant advances have been made in the combined experimental and theoretical understanding of formation, internal structure, and stability of metal jets driven by high explosive. The understanding of jet behavior and interaction with targets of varying complexity permits the design of improved systems to be used against specific targets.

The LSP developed at Los Alamos is a shaped charge with a uranium liner that generates a massive, high-velocity jet of heavy metal. The shape of the liner and the properties of the explosive and the uranium have been carefully tailored to make the jet effective over a range of many meters. This LSP has greater penetrating power than any other shaped charge tested to date. Because of its insensitivity to standoff distance, the LSP has great flexibility and is adaptable to a variety of weapons systems, such as tandem shaped-charge systems (an important countermeasure to reactive armor), where one shaped charge must shoot through another. The LSP technology has been integrated with DoD contractors. Two companies (part of the DARPA/Army/Marine Corps Armor/AntiArmor Blue Team effort) have built LSP tandem shaped-charge warheads. They are presently being evaluated against complex armor systems in the Advanced Technology Assessment Center at Los Alamos.

4. Reactive Armor Explosive. The DOE has a strong expertise in explosives technology because of the explosive lenses used in nuclear weapons. Because of the high interest in reactive armor, we developed a plastic-bonded explosive formulation that meets Army requirements for such applications. The material has very desirable sensitivity characteristics, being tailored to exhibit an energetic reaction under attack from shaped-charge munitions and insensitive to all other forms of attack. The present service explosive, Detasheet $\mathrm{C}$, does not consistently resist an ignition of a burning reaction or detonation when subjected to projectile attack. Burning of the explosive under this circumstance is considered a particularly serious problem because it provides a target signature or marker for offensive action. Armor performance tests were performed by the personnel at U.S. Army Ballistic Research Laboratory, who found that all test requirements were met by the explosive. It was able to resist both ignition and detonation under projectile impact and still perform its intended reactive armor function. The technology has been transferred to the Army and is being considered for use in its reactive armor program. 
5. Battlefield Optical Munition. Responding to the Army and Marine Corps needs for optical countermeasures, we have developed a new class of simple and compact sources of intense bursts of light that use high explosives as the energy storage medium. These devices convert the stored chemical energy into usable directed ultrahigh-intensity light that is devastating to sensors of all types, especially under night conditions. The devices can be used as munitions and not just specialized, complex electro-optic systems. They can be configured in a wide range of calibers as artillery rounds and grenades for existing delivery systems. The optical munition is presently undergoing engineering evaluation, and a production decision will be made upon its completion in 1991.

6. DETEC. Interest began in mid-1983 on the availability and capability of existing computer engagement simulation programs. Los Alamos realized that there was much we could contribute in two specific areas: experience in physics-based simulation and the capability of largescale computations. Physics-based simulation permitted us to address existing or forthcoming systems in the SDI arena (and possibly others) and to provide a real-time, large-scale battle engagement simulation for the SDI. Previous efforts suffered from the very limited front-end time to do a correct analysis of the major issues and near-total lack of time to review proposed solutions for applicability and correctness. Currently, our defense technology evaluation code (DETEC) has been selected as the simulation framework for the SDI National Test Bed and has also been designated as the simulation of choice by the Phase One Engineering Team (POET) of SDIO. The number of interactions with various DoD offices are also growing and strengthening as DETEC matures.

7. Hazard Assessment of Rocket Propellants (HARP). Following the unintended detonation of a Trident rocket motor, the Navy set up a multilaboratory program to investigate the causes. Fracturing of the solid propellant has been identified as a major contributory cause of this and other such events. The mechanisms by which burning of fractured propellant can lead to detonation has been the focus of the combined research effort. The multiple diagnostic capability and the depth of knowledge of explosives initiation at Los Alamos (developed for the nuclear weapons program) gave us a unique opportunity to identify and elucidate the complex processes that lead to detonation. This understanding provides the basis for realistic modeling of detonation behavior (the near-term goal of the program) and eventually of a rocket motor event, guidance in developing safe propellants, and the transfer of dynamic propellant evaluation techniques to the propellant industry.

8. In-Bore Diagnostics. The most promising of the kinetic-energy munition warheads utilizes long-rod penetrators launched from guns. The interior ballistics of rods is not well known because numerical calculations are difficult and experimental measurements are few. An advanced flash-radiographic technique developed at Los Alamos to study the implosion of nuclear weapons was also found to be very useful for studying projectiles in gun barrels. For the first time we have shown experimentally how long metal rods flex as they are accelerated in gun barrels. This information is essential to the success of every long-rod penetrator accelerated in a gun barrel. We will continue our effort with the Army to improve the performance of long-rod penetrators using this technique.

\section{B. Relevant Technologies for Future Applications}

In addition to the examples that we just cited, the technologies described and others being developed hold great potential for future applications to DoD problems.

Much of the technology developed for SDI will have potential application to tactical battlefield problems. In particular, directed-energy weapons, including lasers and microwaves, have application for guidance, antisensor, antipersonnel, and communication suppression missions. Lasers and particle beams also have a potentially significant application in an antisatellite or satellite defense (ASAT/DSAT) role, which may become increasingly important.

The radio-frequency FEL has the potential to become more compact while retaining its advantages of high power, high efficiency, and wavelength tuneability. If these developments are realized, FEL 
application to tactical problems such as airfield defense and fleet defense could make a significant impact. This technology is rapidly advancing because of the intense interest created by SDI and because of the collaborative efforts among Boeing Aerospace, Los Alamos, and universities.

High-power microwaves generated by conversion of high explosive energy to electrical energy may offer the capability to attack targets rich with electronics such as airfields or command centers and to shut down communications, sensors, computers, etc. This technology will benefit from research using the multidisciplinary design and experimental skills associated with the national laboratories teamed with the DoD laboratories and eventually industry.

The computational science area probably has been least explored to date but offers perhaps the greatest potential for impact. The computational science capability at Los Alamos developed in the nuclear weapon program is extensive. Present research in the nonnuclear areas ranges from development of large conventional weapon design codes for advanced munitions to information processing using advanced parallel architectures and advanced artificial intelligence concepts such as neural nets. Cost-effective simulations of complex problems become achievable through these numerical modeling capabilities.

Los Alamos has a collaborative project with the Army's TRADOC, which is attempting to develop more effective and detailed battle simulation capabilities that can be used in training. We believe that the use of computational techniques to address the complex problems associated with defense systems will increase significantly in the future.

The nuclear weapons laboratories have a long-standing expertise in the fundamental understanding and formulation of energetic materials for use in high explosives or propellants. This capability can address issues such as insensitive explosives for increased safety and new explosive compounds for enhanced lethality. Also, if supersmart weapons are to be effective after they reach their target with the expected accuracies, the explosive effects will have to be sufficient to destroy the object. We expect both of these issues to increase in importance and expect the laboratories to make significant contributions.

The materials science capabilities of the national laboratories are very broad because of the needs of the weapons program for special materials ranging from alloys of uranium, to special lightweight plastics, to insensitive high explosives. Los Alamos has a strong technology base in both materials research and materials processing. This base includes $R \& D$ on high-temperature superconductors, advanced ceramics, new high-strength alloys, and superstrong liquid crystalline polymers. This broad base of expertise, coupled with industrial strengths, should provide an important opportunity to make a significant impact on defense programs requiring advanced, high-performance materials.

One example of applying the technology base in the above areas is the largest non-SDI venture that the Laboratory has undertaken for the DoD. It is the DARPA/Army/Marine Corps Armor/Anti-Armor Initiative in which the Laboratory's role as the Advanced Technology Assessment Center involves the responsibility to do independent testing and evaluation of new industrial concepts for armor and penetrators, to serve as a technical coach to industry, and to perform advanced research on key technological issues that involve computer modeling, high explosives, flash $\mathrm{x}$ ray and other diagnostics, and materials research. The technology base capabilities described above will allow a more detailed understanding of the mechanisms involved in munition and armor performance than was previously possible. These data, coupled with our design codes and supercomputers, promise much faster advancement in this area.

One of the research areas that could have a significant future impact on defense is biotechnology. One of the key assets at our Laboratory is the coupling of our life science expertise with our theoretical and experimental physics, chemistry, and material science to produce special capabilities for defense problems. An example is chemical-biological warfare defense. The use of lasers to detect minute amounts of chemical or biological agents has an important application for counterterrorism and lowintensity conflict. This multidisciplinary activity is characteristic of the national laboratory approach to problem solving.

The above examples by no means exhaust the opportunities for the Laboratory's technology base to affect defense problems in the future. The most important point is that, by staying at the forefront of science and technology for the past 45 years, Los Alamos scientists and engineers have been able to address important problems rapidly, flexibly, and in a manner that has not depleted our capabilities for the future. 


\section{Recommendations for Enhancing the DoD Technology Base}

1. Strengthen the DoD Laboratories. The DoD laboratories perform a significant fraction of the 6.1 and 6.2 work and control or manage much of the rest of the technology base. Hence, the quality of the laboratories is critical to the DoD. Many of these laboratories have been plagued for a number of years with inadequate resources. The DSB Study Group pointed out their focus on relevance to near-term military requirements and the difficulties associated with civil service personnel policies in competing for the top technical talent. Consequently, the DoD laboratories, as a group, are not as strong scientifically as they need to be as major keepers of the DoD technology base.

I believe that the DoD laboratories must be strengthened because of their key role in the defense technology base that is so important to U.S. technological superiority and U.S. military doctrine. The DoD laboratories must continue to play a vital role in generating new ideas and options. They can contribute consistently only if they conduct research well in advance of any perceived military needs.

These laboratories must also play important roles in (a) assessing technical alternatives; (b) being smart buyers, that is, developing the internal skills for selecting contractors; (c) troubleshooting; and (d) providing a continuity of effort, free from commercial pressures. The DOE experience has demonstrated that technically strong laboratories also play a key role in integrating the phases of R\&D and the acquisition process. They expedite the transition of technology into fielded systems.

As we have already pointed out, the DoD laboratories must have an environment to attract the best technical and management talent to succeed in these endeavors. The DoD must decide how to strengthen their laboratories. The DSB Study Group recommended several changes for the DoD laboratories, including specified missions focus and critical mass, more administrative flexibility, and some bold personnel experiments to alleviate the civil service problems. I am in general agreement with these recommendations and believe that the DOE laboratories can also help.

Los Alamos recommends the establishment of an extensive personnel exchange program between DoD and DOE laboratories. We believe that this will help some of the DoD laboratories to reestablish close ties with the scientific community, including universities. It will provide a more research-oriented setting and environment for many DoD laboratory personnel. An exchange program would be a step toward integrating universities while keeping research tasks within the defense $R \& D$ setting. These exchanges could involve dozens of DoD researchers at Los Alamos (and perhaps the other DOE Laboratories) for periods up to one year. We see great benefit of Los Alamos personnel spending time in residence at the DoD laboratories to learn more about their technologies and the military requirements of the services, and how technologies may be integrated to meet such requirements.

Such exchanges should be encouraged initially by the DoD funding joint projects between the DoD and DOE laboratories. These projects could range from basic research to advanced technology development. The DOE laboratories could promote the intimate involvement of university faculty, postdoctoral fellows, and possibly graduate students in projects including time-sharing between the two laboratory sites. All of these actions would help to bring about a closer interaction with scientific institutions and a greater visibility for DoD laboratory personnel.

We also strongly encourage an expansion of the Military Research Associate (MRA) programs at the DOE laboratories. This expansion would provide an opportunity for more officers to work in a research environment and receive the technical training that will be important in their future leadership positions. In conjunction with such an expansion, it is important that the services offer more favorable career paths for technically trained officers.

2. DOE Laboratories Teaming with Industry. The DoD depends heavily on private industry-the defense contractors-to maintain its technology base. Private industry helps to involve a broad sector of the nation's science and technology community in generating new ideas for military systems. Sponsoring technology base work by defense contractors also expedites the transition of technology because the manufacture of hardware and systems is the responsibility of the defense contractors.

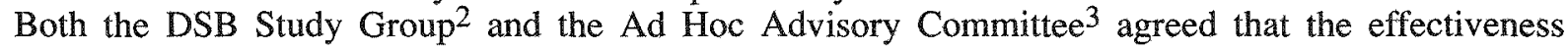


of IR\&D funds has been jeopardized by the government-imposed ceilings and the increased regulatory pressures on how these funds are spent and accounted for. Clearly, these practices must be reexamined.

Our experience at Los Alamos in working in the nonnuclear defense sector has been that the U.S. defense contractors taken as a whole offer a remarkable array of technical capabilities. However, in any one company there is typically less depth or breadth of scientific capabilities than desired. The defense contractors compensate for this lack by subcontracting during proposal preparation or contract performance. Much less teaming occurs during concept and feasibility studies for obvious proprietary reasons. This is an area where the DOE laboratories could help.

We recommend that the defense contractors team with the DOE laboratories early in the concept and feasibility stages of development to extend their technology base with those of the laboratories. Such teaming could be sponsored by the DoD jointly at the laboratories and defense contractors or in some cases could be supported directly by the contractors. To be effective, teaming will also have to involve personnel exchanges and an investment by DoD in the technology bases of the laboratories.

This type of teaming raises many procedural and legal questions, such as fair contracting, conflict of interest, and intellectual property rights. We hope to resolve many of these questions in our current negotiations with DOE on issues of technology transfer to private industry for nondefense applications.

We have initiated teaming arrangements with defense contractors in areas of emerging technologies. These arrangements have been in areas where we have developed expertise that is either not resident in industry (advanced accelerators for neutral particle beams) or not available in sufficient depth to make the necessary technology transition (free-electron lasers). The teaming arrangements are designed to have the Laboratory's science and technical capabilities complement the technical, systems engineering, and manufacturing capabilities of industry. Our current experience will provide an important test case for the future.

3. A Stronger University Role in DoD Research. The general decline in funding for university research must be reversed to strengthen the DoD technology base. Universities not only generate ideas that eventually have potential military impact, but they also provide the most important product of all — highly trained, innovative people. Hans Mark reminds us that many of the major inventions of the past half century at all types of research institutions have not been in response to a firm statement of military or commercial requirements, but rather have occurred by letting ideas and development happen in an apparently random fashion, i.e., jet engines, integrated circuits, radar, lasers, and rockets. ${ }^{12}$

4. An Enhanced Technology Base Role for the DOE Weapons Laboratories. At Los Alamos approximately one-quarter of our effort is performed directly for the DoD, $\$ 240$ million in FY 1988. Therefore, it is no longer a question of should the DOE weapons laboratories work on DoD problems, but rather how do we optimize our contributions? Some of our projects have the desirable characteristics: they are large, complex, and involve both research and technology development. The directed-energy R\&D for SDI falls in this category. The DARPA/Army/Marine Corps ATAC program also has these characteristics. All of these have the strong involvement of industry.

However, many of our projects for DoD are small and resemble job-shop work. They are paperwork and management intensive. We are often asked to work on a specific solution instead of analyzing the problem, suggesting a solution, and solving it. Even for the case of many small projects, we have made some concrete contributions to DoD problems, but we generally are not using our talents in an optimal way. We are typically viewed as another contractor who is closely monitored and controlled. This approach works against flexibility, which is the very characteristic required for success.

We recommend that the DoD and DOE establish a longer-term relationship between the DoD and the DOE weapons laboratories to enhance the laboratories' contribution to the defense technology base. Such a relationship must be based on stable, long-term support that allows the necessary flexibility for the laboratories to contribute in a manner similar to their contributions to the nuclear weapons program.

This recommendation does not suggest that the laboratories need much larger sums of money. In my opinion, a total DoD effort of one-quarter to one-third of the present Los Alamos budget is appropriate and sufficient. However, we do recommend a change in mix from many job-shop efforts towards fewer, more substantial programs. In 1984, the DOE and DoD entered into shared block-funding agreements 
through memoranda of understanding (MOUs) with the Army and with the Office of the Secretary of Defense (OSD). Under the Army agreement, Los Alamos has pursued advanced conventional munitions concepts, defense against chemical and biological warfare, and other advanced concepts.

The MOU with OSD states that "the work will be jointly planned and monitored by the DoD and the DOE. Execution will be managed by the laboratories performing the work in a manner similar to that used in the DOE weapons technology base." We are contributing in research on insensitive high explosives, new concepts for enhanced explosives, and new armor penetrator designs, to name a few. Technical progress has been good on both MOUs, but some management issues still need to be resolved and the transition of technology to the DoD must be improved.

We believe that the MOUs jointly signed by the DOE and DoD provide the proper framework for the DOE laboratories' long-term contributions to the DoD technology base. We urge the two Departments to extend the existing contracts. Future MOUs could address the recommendations made earlier for personnel exchanges with DoD laboratories and teaming arrangements with industry.

\section{Recommendations for Enhancing Technology Transfer and Mission Support}

In Section III-C and the Appendix, I discuss the DOE methodology for R\&D and its transition to hardware development. It may offer some interesting opportunities for some of the DoD requirements. We recommend that DoD undertake an experiment to involve the DOE weapons laboratories in concept development, systems development, and production in a manner similar to their role in the nuclear weapons program.

A few projects such as advanced lethality warheads or special armors should be carefully selected and a methodology should be jointly devised. In such proposed experiments, the DOE weapons laboratories would be involved with the services and DoD laboratories at the earliest conceptual formulation stage. We could picture the following scenario. The DOE weapons laboratories could help identify and evaluate concepts and suggest and evaluate technologies. In the next phase of concept feasibility, this team should be joined by defense contractors who have an interest in providing the final engineered system. In this important phase, exploratory R\&D helps to develop some of the enabling technologies. It also includes proof-of-principle demonstrations of concepts, components, and some systems. Clearly, there must be continued dialogue with the services about the operational requirements. Initial design definitions and cost studies would follow. This same team with increased industrial participation would then develop a tested, manufacturable systems design, a full-scale prototype.

With this type of methodology, which involves both the DOE weapons laboratories and the DoD laboratories, we believe that technology transition can be expedited and the technical feasibility and field utility can be established before committing to a full-scale engineering design. The subsequent phases of full-scale engineering, production, and deployment are primarily the responsibility of industry and the services. Some involvement of DOE and DoD laboratories should remain to help resolve specification issues, production problems, and other surprises that often stretch out milestones and run up costs.

We have discussed the approach described here with the Army for possible experiments in areas such as composite penetrators and microwave munitions. Although this approach is new and bold, it may be a great opportunity to bring to bear the talents of the DOE weapons laboratories and their approach to weapons development. If it works, it may expedite the transition of technology to military systems.

We are also currently using the front end of this approach in the development of the neutral particle beam for potential SDI applications. Los Alamos is teamed with the Army and Grumman Aerospace Corporation in building the Ground Test Accelerator that will demonstrate the weapon-level parameters of an entry-level neutral particle beam system. The Laboratory initiated the project and brought in industry because of its engineering and systems expertise. The early involvement of industry will help to make the technology transition from the Laboratory to industry. As this concept moves into future phases of development, we expect industry to play a larger role but with continued Laboratory technical involvement.

The DOE weapons laboratories may also be able to provide some mission support in areas where their technologies are applicable. We are currently working with the Army to use our extensive experience in large-scale computations and our expertise in expert systems to study battlefield simulations. We expect 
that we can help with the overwhelming problem of information monitoring, processing, and distribution that will be present in the battlefield of the future.

We are also currently exploring ways that our technological expertise can support the Air Force laboratories and specific programs in the area of air base operability. There appear to be several opportunities to address key issues that could use our capabilities in computer modeling, simulation, weapon effects, and countermeasures.

\section{CLOSING STATEMENT}

In your letter of invitation for this hearing you have asked, "How can the DOE Laboratories contribute to and strengthen the defense technology base?" The Los Alamos response-based on over 45 years of experience as a GOCO laboratory and of service to this nation's security-is simple: emulate the successful and applicable parts of our experience and make more use of our capabilities.

For 45 years, Los Alamos has been a GOCO laboratory, owned by the government and operated for it by the University of California. Our primary mission continues to be the design, development, and testing of the nuclear weapons that are the basis of the nation's nuclear deterrent. I believe the nation has been well served both in the quality of our technical performance and in the quality of the management of the laboratories. Our record is not perfect, but there are some enduring strengths that can now be employed in broader service to the nation.

We learned early and quickly that the path to success in applied science must be built on a thorough understanding of the basic sciences, technologies, and engineering involved. That awareness started during World War II, when some of the nation's greatest scientific talent worked with us, and it has continued because of the management ethic of the University of California and the wisdom of the DOE and its predecessor agencies. As a result of this awareness, we and the other DOE laboratories have a broad base of science and technology and possess world-class expertise on a wide range of topics of importance to national security. Because of this expertise, the laboratories have played an important role in almost every aspect of the nuclear weapons program. Our contribution, perhaps greatest in the design, development, and testing phase, has been significant and supportive to the production, stockpiling, and retirement phases as well. We have learned how to work with and help every part of the vertically integrated production complex. Because of our broad-based approach to problem solving and because we have been able to offer competitive salaries, we have been able to recruit and retain highly competent staff and maintain dynamic and creative laboratories. And finally, we have shown repeatedly that we can focus our diverse resources on important national problems quickly and effectively.

During times of great budgetary stress, this nation must optimize the contributions of all sectors of its science and technology community to maintain the defense technology base. Others have studied the DoD and private sector contributions and have made some far-reaching recommendations. I have addressed mainly the issue of how the DOE laboratories can contribute. On behalf of Los Alamos, I have made the following specific recommendations:

- Strengthen the DoD laboratories to fulfill the broad range of missions expected of them. To strengthen their scientific and technological capabilities, we recommend a personnel exchange with the DOE laboratories. This exchange should include joint research and development projects.

- Encourage teaming of private defense contractors and the DOE laboratories early in the concept and feasibility stages of development to extend the contractor's technology base with those of the laboratories.

- Have DoD undertake an experiment to involve the DOE weapons laboratories in concept development, systems development, and production on a few specific concepts in a manner similar to their role in the nuclear weapons program.

- Revitalize interest in careers in science and technology. The issues associated with the diminished interest by young people in careers in science and technology are important. There 
are many proposals for accomplishing the needed reawakening of interest as well as for the revitalization of university $R \& D$ facilities. We urge you to examine these issues.

These recommendations are aimed primarily at promoting a more stable, long-term relationship between the DOE weapons laboratories and the DoD. A more stable relationship would benefit not only the nation's defense technology base, but also the DOE and the nuclear weapons program.

\section{REFERENCES}

1. Paul Kennedy, The Rise and Fall of the Great Powers (Economic Change and Military Conflict from 1500 to 2000), Random House, New York, 1987.

2. "Technology Base Management," report of the Defense Science Board Summer Study, Office of the Under Secretary of Defense for Acquisition, August 1987.

3. Report of the Ad Hoc Industry Advisory Committee, Subcommittee on Defense Industry and Technology, Senate Armed Services Committee, February 5, 1988.

4. "RDT\&E Programs (R-1)," Department of Defense Budget for Fiscal Years 1988 and 1989, January 1987.

5. F. C. Ikle and A. Wohlstetter, "Discriminate Deterrence," The Report of the Commission on Integrated Long-Term Strategy, U.S. Department of Defense, January 11, 1988.

6. Flora Lewis, "Moscow at a Crossroads," New York Times, December 11, 1987.

7. S. S. Hecker, "High-Temperature Superconductivity," statement before the U. S. House of Representatives Committee on Science, Space, and Technology, June 10, 1987.

8. S. S. Hecker, "Los Alamos National Laboratory: A Look at the Future," statement before the U.S. Senate Committee on Armed Services, Subcommittee on Defense Industry and Technology, at the Oversight Hearing on the Department of Energy's Nuclear Weapons Laboratories, November 7, 1987, Albuquerque, New Mexico.

9. S. S. Hecker, statement to the House Armed Services Committee, Subcommittee on Procurement and Military Nuclear Systems, FY1989 Authorization Hearing, March 3, 1988.

10. Report of the White House Science Council, Federal Laboratory Review Panel, Office of Science and Technology Policy, May 1983.

11. Report of the President's Blue Ribbon Task Group on Nuclear Weapons Program Management, July 1985.

12. Hans Mark and Arnold Levine, "The Management of Research Institutions: A Look at Government Laboratories," NASA SP-481, 1984. 



\section{APPENDIX \\ NUCLEAR WEAPONS ACQUISITION PROCESS \\ SYNOPSIS OF ACTIVITIES AND LABORATORY ROLES \\ AND RESPONSIBILITIES}

\section{ACTIVITY}

\section{Prephase 1}

Military departments maintain continuing search for new mission needs and for weapon systems to satisfy these needs.

\section{Phase 1 (Concept Studies)}

The purpose of the weapon concept studies is to define weapon concepts related to a perceived or expressed need and to facilitate a conclusion by the DoD on the advisability of proceeding with a joint Phase 2 study. A Phase 1 study may be initiated by either the DoD or DOE.

\section{Phase 2 (Feasibility Study)}

A feasibility study (a joint DOE-DoD effort) determines the technical feasibility and identifies those aspects of the nuclear design, development, testing, production processes, and resource availability likely to be determining factors for developing and producing a nuclear weapon of the desired characteristics for a particular weapon system.

\section{LABORATORY ROLES AND RESPONSIBILI- TIES}

The Laboratory continues development of new technologies and concepts in anticipation of possible future needs of the military for national defense and maintains contact with DoD.

The Laboratory maintains contact with cognizant DoD departments to exchange information on weapon concepts and requirements; starts participation in process to develop draft military characteristics (MCs) and outline of stockpile-to-target sequence (STS); conducts internal Phase 1 study of concepts, technologies, and capabilities; and prepares a Phase 1 report.

The Laboratory's milestones, deliverables, and activities for this Phase are preparation of appropriate designs for consideration during the study and inclusion of the Phase 2 report, participation in the refinement of draft MCs and STS, and provision of appropriate information on the proposed nuclear designs, development, testing, and resource activity. 


\section{ACTIVITY}

\section{Phase 2A (Design Definition and Cost Study)}

The purpose of the design definition and cost study (a joint DOE-DoD effort) is to identify the baseline design(s) that best balance resources and requirements to establish a tentative development and production schedule and to define a DOE-DoD division of responsibilities for development and production.

\section{Phase 3 (Development Engineering)}

The development engineering activity is the period for establishing a tested, manufacturable nuclear weapon design, for describing the current design status to provide an update on previous cost estimates, and for stating what initial operational capability (IOC) can be accomplished.

\section{Phase 4 (Production Engineering)}

Production engineering is initiated through DOE/AL to support initial production activities for a new warhead.

\section{LABORATORY ROLES AND RESPONSIBILI- TIES}

The Laboratory's milestones, deliverables, and activities for this Phase are to provide the nuclear baseline design(s) definition(s) in sufficient detail to allow cost/performance tradeoff studies; to participate as the Laboratory's principal representative in associated analysis, hardware development, and tests as required to define the nuclear design; and to participate in cost/performance trade-off studies as required.

The Laboratory's milestones, deliverables, and activities for this Phase are to develop a tested, manufacturable nuclear weapon design that meets the MCs and STS to ensure that they are acceptable and to provide definitive nuclear test requirements, hardware, development, tests, and design drawings.

The emphasis within the Laboratory begins to shift from development to completed designs for production. Even though the weapons program is defined to be in Phase 4, some Phase 3 development engineering may continue. Phase 4 ends when the design laboratories issue complete engineering releases (CER) for all components, subassemblies, and assemblies. 


\section{ACTIVITY}

\section{Phase 5 (First Production)}

First production is the transition period during which the plants achieve the production rate required to support Phase 6 quantity production. During this period, the design laboratories prepare and submit the Final Weapon Development report (FWDR), which updates the preliminary and interim development reports and provides a basis for a statement accepting the weapon as a "standard stockpile" or "limited stockpile" item.

\section{Phase 6 (Quantity Production and Stockpile)}

Quantity production and stockpile (Phase 6) is the production of war reserve weapons at rates necessary to support approved DoD requirements. This phase also includes spare parts, components, and ancillary equipment. Phase 6 is scheduled to support the weapon quantities authorized by the Nuclear Weapons Stockpile Memorandum (NWSM) and laboratory testing, joint flight testing, and stockpile confidence tests (SCT).

\section{Phase 7 (Retirement)}

Retirement begins with the first physical withdrawal of weapons from the operational stockpile and their return to the DOE in accordance with the NWSM. The weapons are returned to the Pantex Plant for disassembly and inspection. The information gained from the inspections of components is valuable for possible use on followon systems.

\section{LABORATORY ROLES AND RESPONSIBILI- TIES}

Laboratory representatives continue to monitor production activities. The design laboratories prepare and submit the Final Weapon Development report to prepare the major assembly release (MAR) for approval by DOE/AL and release to DoD. This action must occur before quantity production.

The Laboratory continues to monitor production activities with specific responsibilities in the stockpile evaluation program. A major responsibility is the evaluation of a problem that has developed or is developing in some portion of the weapon and the specification of a solution to the problem.

The Laboratory participates in this phase through observance of the disassembly of the retired weapons and possible use of the information gained from the inspections for use in design of future systems and/or modification of existing stockpile systems. 


\section{WEAPON DEVELOPMENT}
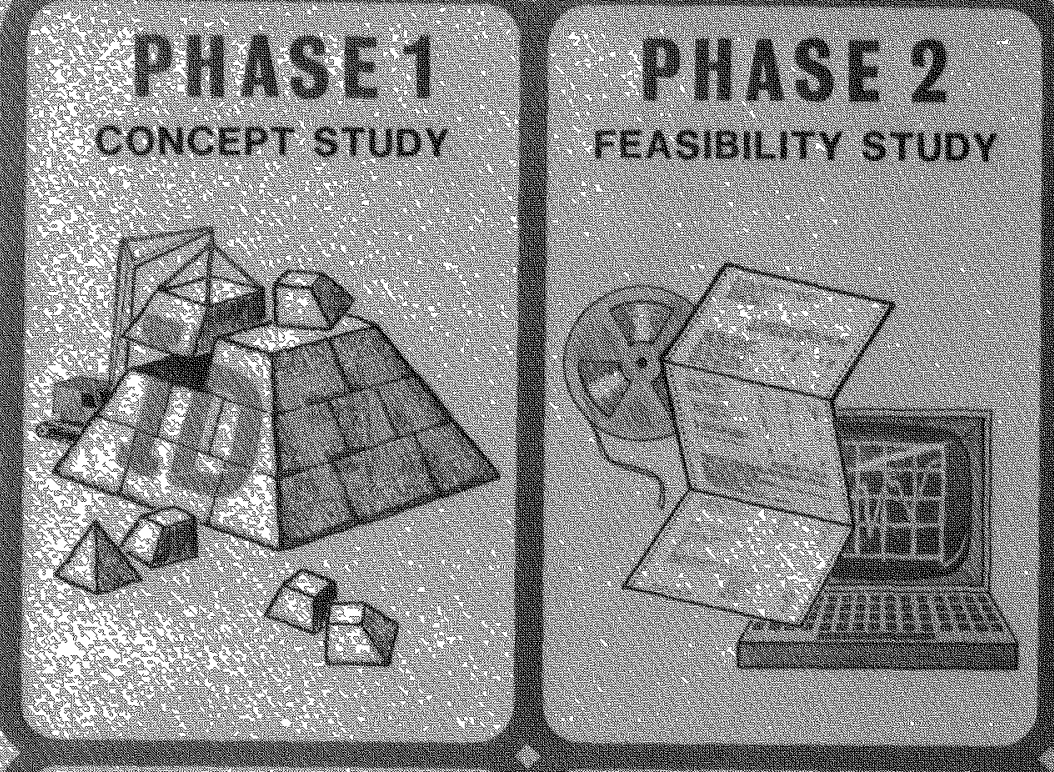

\section{PHASE 2A DESIGN DEFINITION} AND COST STUDY

\section{PHASE 3} DEVELOPMENT

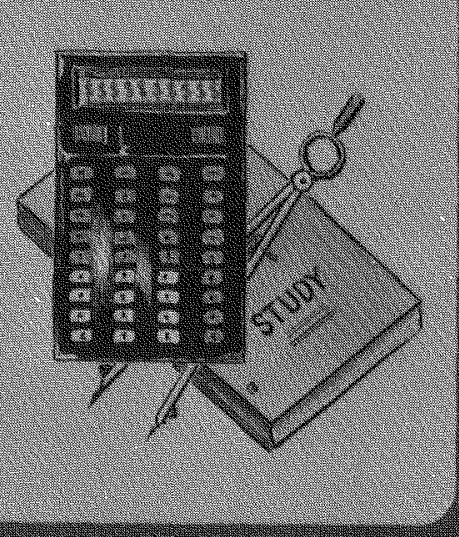
ENGINEERING

PHASE 4 PRODUCTION ENGINEERING

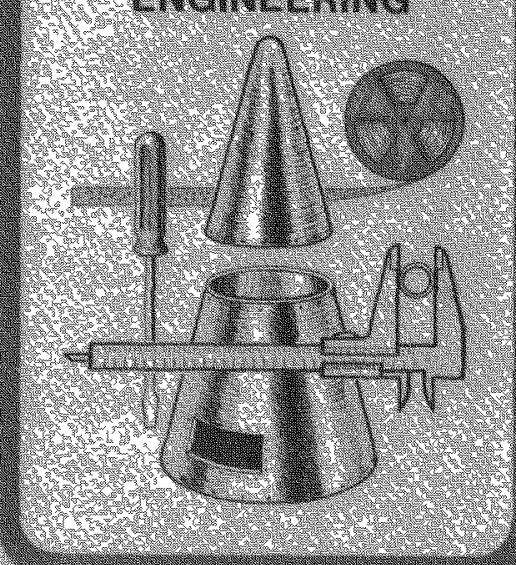

PHASE 5 FIRST PRODUCTION

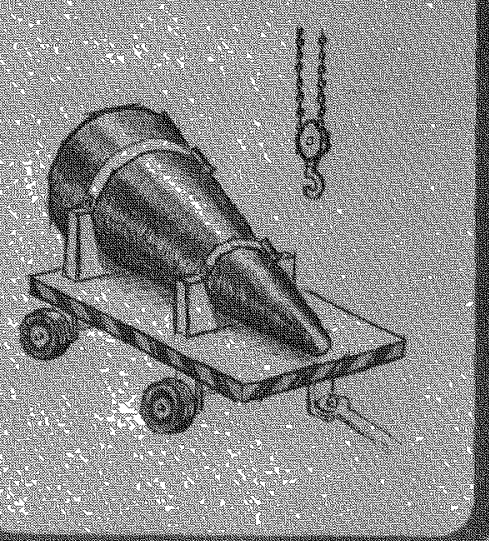

PHASE 6 QUANTITY PRODUCTION \& STOCKPILE

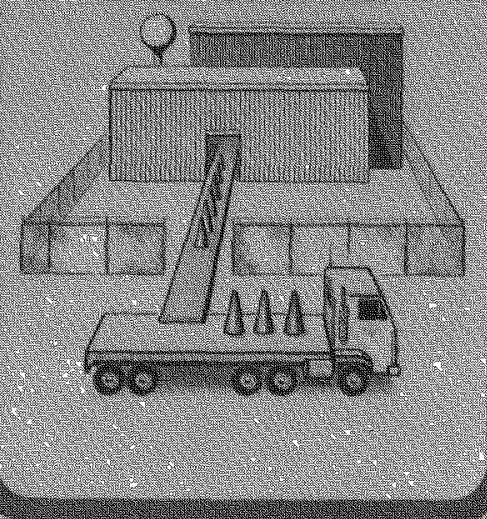

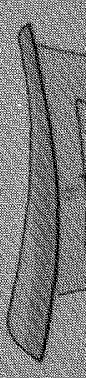
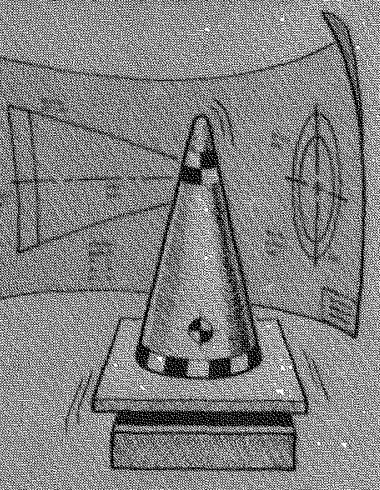

PHASE 7 RETIREMENT

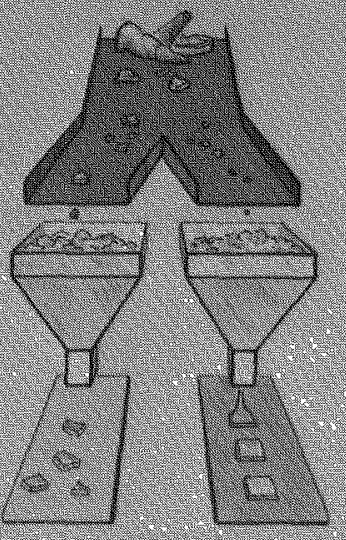




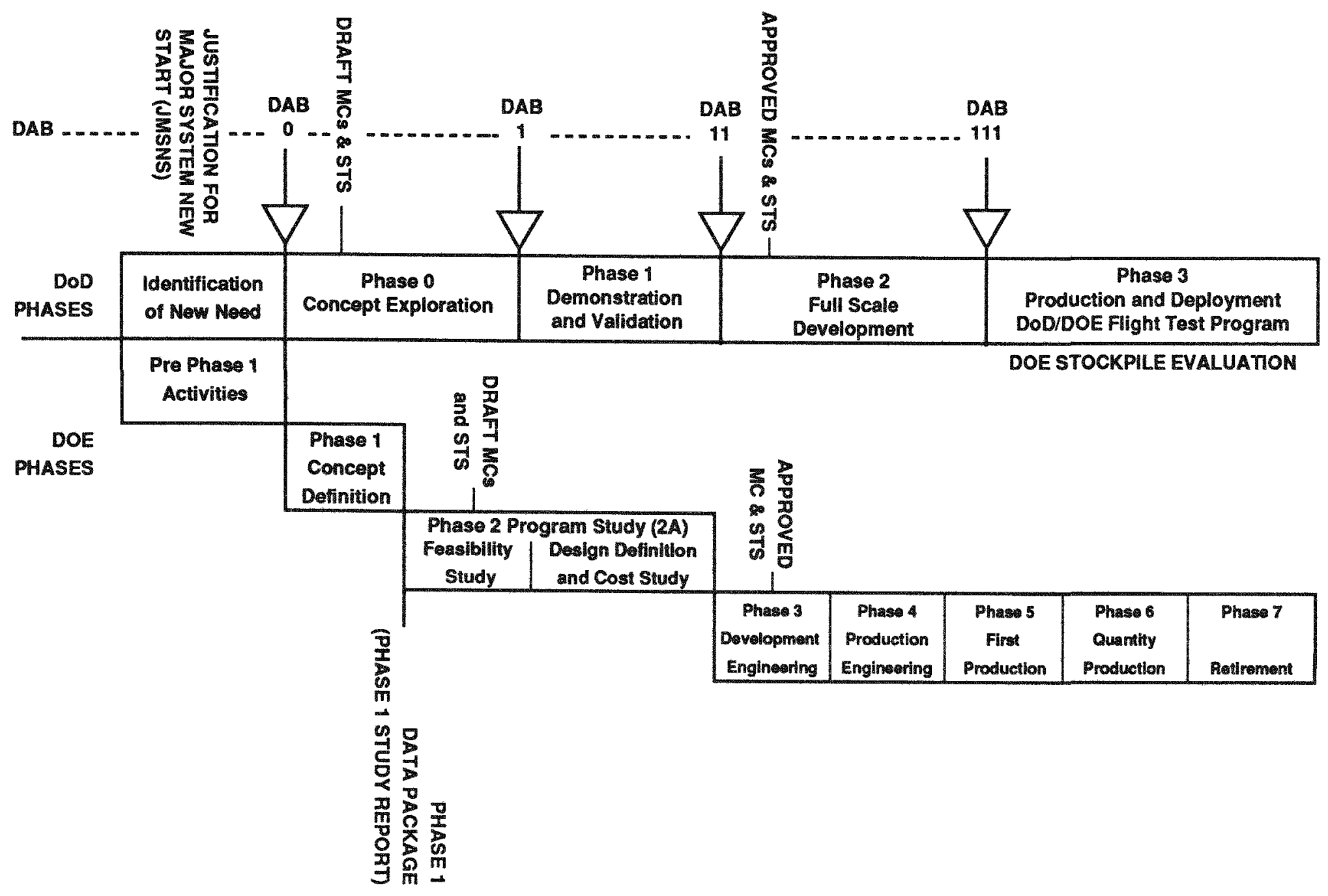

COMPARISON OF DOD AND DOE PROGRAM PHASES 
This report was prepared as an account of work sponsored by an agency of the United States Government. Neither the United States Government nor any agency thereof, nor any of their employees, makes any warranty, express or implied, or assumes any legal liability or responsibility for the accuracy, completeness, or usefulness of any information, apparatus, product, or process disclosed, or represents that its use would not infringe privately owned rights. Reference herein to any specific commercial product, process, or service by trade name, trademark, manufacturer, or otherwise, does not necessarily constitute or imply its endorsement, recommendation, or favoring by the United States Government or any agency thereof. The views and opinions of authors expressed herein do not necessarily state or reflect those of the United States Government or any agency thereof. Printed in the United States of America
Available from

National Technical Information Servie:

US Department of Commerce

5285 Port Royal Road

Springfield, VA 22161

Microfiche (A01)

NTIS

Page Range Price Code

$001-025$

026-050

051-075

076-10

101-12.

$126-150$

\section{$\mathrm{A} 02$}

AOS

$\mathrm{AO4}$

A05

$\mathrm{A} 06$
$\mathrm{~A} 07$
NTIS

Page Range

\section{1-175}

$176-200$

201-225

226-250

251-275

$276-300$
Price Code

\section{$\mathrm{AOB}$}

A09

A10

A11

A12
A13
NTIS

Page Range

301-325

326-350

351-375

376-400

401-425

426-450 rice Cod

\section{A14}

A15

A16
A17

A17

A19
Page Range Price Code

$451-475$

476-500

$501-525$

526-550

$551-575$

576-600

601-up"
A20

A21

A22

A24

A25 


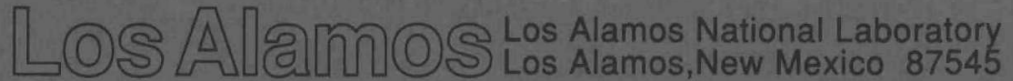

Los Alamos National Laboratory is operated by the University of California for the United States Department of Energy under contract W-7405-ENG-36. 